\title{
PROCESSOS COMUNICACIONAIS NOS CÍRCULOS DE MULHERES E SUAS RELAÇÕES COM A TEOLOGIA ECOFEMINISTA
}

\author{
Patricia Santos Machado*
}

\begin{abstract}
RESUMO
Buscaremos apresentar as características principais do movimento dos círculos de mulheres, suas relações com os preceitos da teologia ecofeminista e suas reverberações na comunicação entre as mulheres. Verificamos uma possibilidade de formas mais orgânicas e colaborativas nos processos comunicacionais nos círculos, processos estes que apresentam uma alternativa à estrutura social e de comunicação vertical/fálica/linear típica do androcentrismo. Os círculos possuem características relacionadas às rodas de cura presentes nas religiões xamânicas e têm uma íntima conexão com a prática da espiritualidade não institucionalizada e de pluralidade religiosa. A metodologia escolhida é Hermenêutica de Profundidade (J. B. Thompson) e os referenciais teóricos são: os estudos do imaginário, a comunicação, a teologia ecofeminista e o ecofeminismo.

Palavras-chave: imaginário; processos comunicacionais; teologia ecofeminista; círculos de mulheres; espiritualidade feminina.
\end{abstract}

\section{COMMUNICATION PROCESSES IN WOMEN'S CIRCLES AND THEIR RELATIONSHIPS WITH ECOFEMINIST THEOLOGY}

\begin{abstract}
This article seeks to present the main characteristics of the movement of women's circles, its relationship to the precepts of ecofeminist theology, and their reverberations in communication among women. We verified a possibility of more organic and collaborative forms in the communication processes in the circles, processes that present an alternative to the social and vertical / phallic / linear communication structure typical of androcentrism. The circles have characteristics related to the healing wheels present in shamanic religions, and they
\end{abstract}

* Mestre em Comunicação Social pela Universidade Metodista de São Paulo. Pesquisadora do Grupo de Pesquisa Mídia, Religião e Cultura (MIRE) da UMESP. 
have an intimate connection with the practice of non-institutionalized spirituality and religious plurality. The methodology chosen is Depth Hermeneutics (J. B. Thompson) and the theoretical references are: imaginary studies, communication studies, ecofeminist theology and ecofeminism.

Keywords: imaginary; communicational processes; ecofeminist theology; women's circles; female spirituality

\title{
PROCESOS COMUNICACIONALES EN LOS CÍRCULOS DE MUJERES Y SUS RELACIONES CON LA TEOLOGÍA ECOFEMINISTA
}

\begin{abstract}
RESUMEN
Presentaremos las características principales del movimiento de los círculos de mujeres, sus relaciones con los preceptos de la teología ecofeminista y las reverberaciones en la comunicación de los miesmos. Se verificó una posibilidad de formas más orgánicas y colaborativas en los procesos comunicacionales en los círculos, procesos que presentan una alternativa a la estructura social y de comunicación fálica/lineal típica del androcentrismo. Los círculos poseen características de las ruedas de curación presentes en las religiones chamánicas y tienen una conexión con la práctica de la espiritualidad no institucionalizada y de pluralidad religiosa. La metodología elegida es Hermenéutica de Profundidad (J. B. Thompson) y los referentes teóricos son: los estudios del imaginario, la comunicación, la teología ecofeminista, el ecofeminismo.

Palavras-chave: imaginario; procesos comunicacionales, teologia ecofeminista; círculos de mujeres; espiritualidad feminina
\end{abstract}

\section{INTRODUÇÃO}

Este artigo busca apresentar as características principais do movimento dos círculos de mulheres e discutir sua relação com os preceitos da teologia ecofeminista e suas reverberações na comunicação e partilha de experiência entre as mulheres contemporâneas.

A partir disto, é possível encontrar formas mais orgânicas e colaborativas nos processos comunicacionais nos círculos, processos estes que apresentam uma alternativa à estrutura social e de comunicação vertical/fálica/linear. Ao fomentar a noção de comunidade, de organismo, de ciclicidade e de descentramento no indivíduo, tais processos comunicacionais transferem o foco para as relações mais orgânicas 
entre as mulheres. A partilha de experiências e conhecimento de forma orgânica dá a tônica da comunicação e sobressai-se quando comparada à simples troca de informações. Dito isto, identificamos uma relação com as teorias de Dominique Wolton (2010) e as ideias sobre a distinção e as conexões entre informar e comunicar. Contudo, em tratando-se dos círculos, nota-se a diferença entre comunicação e informação, mas não a dissociação absoluta entre os conceitos. Assim, recorreremos às ideias de Michel Maffesoli (2003; 2010) para explorar essas distinções e encontros entre eles.

A estrutura "litúrgica" dos círculos possui particularidades que os conectam com as rodas de cura presentes nas religiões nativistas/xamânicas e tem uma íntima ligação com a prática da espiritualidade não institucionalizada, além de ser caracterizada pela pluralidade religiosa. Para dar suporte às nossas reflexões, recorreremos aos trabalhos de Ivone Gebara (1997) e Rosemary Radford Ruether (2000) e as teorias da teologia ecofeminista.

O ecofeminismo espiritualista também é aqui considerado, ainda que indiretamente, a principal base ideológica dos círculos de mulheres, visto que ao relacionar o sagrado ao planeta e à própria mulher, também se ocupa de questões sobre a sustentabilidade e a preservação do meio ambiente, tanto subjetiva como coletivamente. Maria Mies e Vandana Shiva (1993) e também Regina Célia Di Ciommo (1999) serão nossas fontes sobre o assunto.

A metodologia escolhida por nós é a Hermenêutica de Profundidade (John THOMPSON, 2011), daqui em diante referida por HP, que se caracteriza pela análise sócio-histórica; a análise formal ou discursiva; e a interpretação/reinterpretação das formas simbólicas produzidas, transmitidas e recebidas que estão presentes nas ideologias e na comunicação.

Para Thompson (2011, p. 355) a HP “coloca em evidência o fato de que o objeto de análise é uma construção simbólica significativa, que exige uma interpretação". Dito isto, a importância da interpretação e também da reinterpretação - das formas simbólicas possibilita uma perspectiva crítica de análise cultural.

Enquanto formas simbólicas, os fenômenos culturais são significativos assim para os atores como para os analistas. São fenômenos 
rotineiramente interpretados pelos atores no curso de suas vidas diárias e que requerem a interpretação pelos analistas que buscam compreender as características significantes da vida social (THOMPSON, 2011, p. 181).

As ferramentas de análise que constituem a HP permitem que a pesquisa realizada sob esta metodologia agregue, dependendo das necessidades e características do objeto analisado, outros métodos à pesquisa.

\section{SOBRE CÍRCULOS, COMUNICAÇÃO ENTRE MULHERES E ESPIRITUALIDADE FEMININA}

Para entendermos a dinâmica dos círculos de mulheres é necessário que desconstruamos uma série de conceitos e pensamentos androcentrados e lineares. Mas, antes mesmo de compreender os círculos femininos é bom que reflitamos sobre o que os círculos (e a forma circular) representam.

O círculo é em primeiro lugar um ponto estendido. O ponto e o círculo têm propriedades simbólicas comuns: perfeição, homogeneidade, falta de distinção ou divisão. (...) constituem a manifestação do Ser único universal e não manifestado (...) O movimento circular é perfeito, imutável, sem começo nem fim (...) O círculo é usado para simbolizar também o céu, de movimento circular e inalterável. Em outro nível de interpretação, o céu em si torna-se um símbolo do mundo espiritual, invisível, transcendente. (...) Mais especificamente, o círculo simboliza o céu cósmico e, particularmente, as suas relações com a terra. Neste contexto, "o círculo simboliza a atividade do céu, a sua inserção dinâmica no cosmos, sua causalidade, a sua exemplaridade, o seu papel providencial”. Além disto, há ligações com os símbolos da divindade associada à criação, cuja vida ocorre, regula e organiza (...) De acordo com os textos de filósofos e teólogos, o círculo pode simbolizar a divindade considerada, não apenas em sua imutabilidade, mas também a sua bondade como difusora origem, de subsistência e consumação de tudo coisas; o alfa e o ômega. (...) O círculo simboliza o sopro da divindade sem começo nem fim (Jean CHEVALIER, 1986, p. 300-301).

Nestes significados encontramos a relação do círculo com o Sagrado e com a noção de divindade suprema. Utilizando ainda o clássico Dicio- 
nário de Símbolos de Chevalier (1986, p.302-304) podemos destacar a presença das formas circulares em diversas culturas e tradições religiosas do planeta. Para os zen-budistas, o círculo representa a perfeição interior e a harmonia espiritual; os babilônios utilizavam os círculos para medir o tempo; a trindade cristã é representada por três círculos conectados uns aos outros; os nativos norte-americanos os identificam com as fases da lua; para os celtas, os círculos tinham funções mágicas e estão presentes em diversos de seus mitos; no islamismo, o círculo representa a mais perfeitas das formas.

Carl Gustav Jung (1978, p. 58) cita uma frase icônica do filósofo grego Empédocles, na qual relaciona o círculo à divindade quando diz que "Deus é uma figura espiritual (geométrica), cujo centro se encontra em toda parte e cuja periferia não está em lugar nenhum". Além disto, conecta o imaterial e o material, visto que representa o inefável e também o concreto.

Apesar dos círculos e rodas de cura que, compostos por mulheres e homens serem algo que faz parte da própria história humana, a popularização dos círculos de mulheres deu-se no início do século XXI, através da proposta da psicanalista junguiana, Jean Shinoda Bolen (2003). Em 1999 ela publicou "O Milionésimo Círculo", uma espécie de manual para a criação e manutenção dos círculos de mulheres que propõe a importância da expansão da (re)união das mulheres em rodas. No website oficial, a "visão" da iniciativa é descrita como:

Uma proliferação de círculos com um centro espiritual que se converte em uma força curativa mundial que resgata os valores femininos de relacionamentos, de cuidado, de interdependência, a uma cultura global onde a hierarquia, conflito e competição, o poder sobre os outros e a exploração dos recursos da Terra são os valores dominantes. Nossa meta é celebrar o milionésimo círculo como uma ideia que chegou no momento certo'.

Original em inglês: "A proliferation of circles with a spiritual center becomes a worldwide healing force by bringing feminine values of relationship, nurturing, and interdependency into a global culture in which hierarchy, conflict and competition, power over others and exploitation of the earth's resources are dominant values. Our aim is to celebrate the millionth circle as an idea whose time has come." Disponível em: <http://millionthcircle.org/About/vision.html> . Acesso em: 20 maio 2016. 
Da ideia central dessa iniciativa salta a compreensão de que, através da formação dos grupos circulares de mulheres, uma massa crítica seja alcançada que colabore com a quebra do paradigma que despreza o que é típico da dimensão feminina, do imaginário e supervaloriza o que é androcentrado. Numa espécie de "androcracia”, a maioria das questões e conceitos humanos - especialmente na tradição ocidental - foi pautada a partir do ponto de vista do macho² da espécie humana. Segundo Jean Shinoda Bolen (2003, p. 109-110):

A civilização ocidental é a história do patriarcado, uma dominante e hierárquica história de poder e intelecto que, juntos, nos levaram a altíssimos níveis de tecnologia e à possibilidade de destruição de nosso planeta. Nossas florestas tropicais estão sendo devastadas e queimadas. Nosso ar, água e terra poluídos. [...] Lucro e poder como regras vigentes levam a isto e a guerras. Estão produzindo uma terra devastada.

Inspirada na "Teoria do Campo Mórfico" (do biólogo inglês Robert Sheldrake) e na alegoria do "Centésimo macaco" usada pelos ativistas anti-nucleares, Bolen (2003) sugere que a formação de um milhão de círculos de mulheres no planeta pode modificar - a partir do inconsciente coletivo - o comportamento, os hábitos, a comunicação e as relações socioculturais humanas, bem como a relação da espécie com a própria Natureza.

Quando um número crítico de pessoas transforma sua maneira de pensar e agir, a cultura também se transforma e uma nova era se inicia. Uma vez que os princípios são compreendidos, o significado dos Círculos de Mulheres pode ser visto como um movimento evolucionário e revolucionário que está escondido por trás de uma imagem aparente: parece ser apenas um grupo de mulheres reunidas conversando, mas cada mulher e cada Círculo está contribuindo para algo maior (Jean BOLEN, 2003, p. 16).

Aquilo que compreende a androcracia também envolve questões sociais, étnicas, econômicas e culturais. Contudo, neste momento não iremos abordar estas nuances, por conta do recorte escolhido neste artigo. 
Sobre a importância da criação de novos círculos, Jean Shinoda Bolen (2003, p. 30) explica que "cada círculo é uma recuperação da forma arquetípica que emerge de cada Círculo de Mulheres que já existiu e cada Círculo, por sua vez, agrega energia ao campo arquetípico que tornará mais fácil a criação do próximo".

Deste modo, também podemos dizer que os círculos de mulheres podem ser parte das transformações típicas da pós-modernidade e que expressam a "saturação" (Michel MAFFESOLI, 2010) da modernidade. Os círculos são, ao mesmo tempo, uma expressão arcaica e de vanguarda, pois contém elementos ancestrais ${ }^{3}$ e também características consideradas "da nova era". Mais uma vez, a compreensão desta ambiguidade dá-se através da noção da ciclicidade, pois a linearidade isolada - de lógica moderna progressista e dicotômica - não dá conta de explicar o fenômeno e sua complexidade típica da pós-modernidade.

Assim, julgamos que a "nova era", descrita por Jean Bolen (2003), não se trata de uma progressão para algo novo ou ainda de uma simples regressão ao passado. Há um caminho do meio ou ainda um "retorno ao ventre" (Michel MAFFESOLI, 2010), inclusive para quebrar a dicotomia entre o passado e o futuro. Recorremos ao pensamento maffesoliano para alinharmos nossa reflexão à noção de "ingressão" do sociólogo francês.

Necessidade no tornar-se necessário e inelutável de tudo, de todos, de voltar atrás, de retornar ao ventre, de voltar às raízes. No ritmo

\footnotetext{
Identificamos em alguns círculos uma espécie de "romantismo" ao propagar a ideia de um retorno a um hipotético "paraíso feminino perdido", inclusive ao afirmarem como base litúrgico/ histórica/mítica de suas reuniões, alguns elementos retirados de algumas obras de ficção e de cunho midiático, tais como o livro "A Tenda Vermelha". A narrativa, que envolve a personagem bíblica Diná, não trata de uma reinterpretação teológica feminista do Gênesis, mas sim de um romance ficcional. Nas palavras da própria autora, Anita Diamant, a narrativa não tem relação direta com a bíblia. Ela diz que não se trata de uma (re)interpretação das escrituras e que ela usou da liberdade como romancista para criar uma boa história. Importante dizer que as tendas femininas (também chamadas de "tendas vermelhas") fazem parte de outras culturas, como as dos nativos norte-ameríndios, mas não da cultura judaica. Julgamos pertinentes as reinterpretações dos mitos a partir da perspectiva feminina, contudo, a obra citada não trata disto. Pretendemos desenvolver trabalhos futuros no sentido de analisar esses fenômenos (Citação do comentário da autora, retirado do artigo "Stepping into 'Red Tent'”. Disponível em: < http://www.christianitytoday.com/ct/2014/december-web-only/stepping-into-red-tent. html>. Acesso em: 27 jul. 2016).
} 
da vida, aspirar a esse ponto fixo que é a fonte. Essa regressão, essa volta a um estado anterior, é uma prática habitual no que diz respeito a uma carreira individual. Talvez seja preciso admiti-la, igualmente, para a "carreira", o caminhar societal. O termo regressão não é, no caso, o mais conveniente. Talvez fosse necessário dedicar-se a destacar que se trata, mais, de uma ingressão. Ou seja, uma força interna, uma energia que se focaliza no hic et nunc. Ingresso versus Progresso (Michel MAFFESOLI, 2010, p. 83).

Segundo Jean Bolen, "o que o planeta necessita agora é de uma infusão do tipo de sabedoria que as mulheres têm e a própria forma do círculo é a materialização dessa sabedoria". Citando McLuhan, Bolen diz que a frase "o meio é a mensagem" revela bem a natureza comunicativa dos círculos, pois, por não possuírem uma hierarquia, os círculos são a manifestação da equidade. Enfim, Bolen afirma que desta forma, "a cultura se conduz quando ouve e aprende a partir da contribuição de todos" (Jean BOLEN, 2003, p. 28). Em “O Milionésimo Círculo", ela defende que as experiências compartilhadas dentro dos círculos de mulheres podem influenciar positivamente as relações externas, pois podem determinar um modelo para uma "comunicação mais honesta e duradoura" não só com os outros, mas também consigo mesma (Jean BOLEN, 2003, p. 32).

Desta maneira, isto pode fazer você alterar as estruturas patriarcais de seus relacionamentos. À medida que transformamos nossas relações pessoais, esta transformação se espalha [...] Um Círculo é um lugar igualitário de aprendizado [...] Um Círculo confiável tem um centro espiritual e respeito pelos seus limites. É um agente poderosamente transformador das mulheres que o compõem. Círculos também funcionam como grupos de apoio: se você quer transformar algo em sua vida ou em você mesma, o Círculo é uma base segura para suas tentativas. Em um ambiente patriarcal, um Círculo de iguais pode ser como uma ilha onde se pode falar livremente e rir. Ele nos faz conscientes dos contrastes, através dos quais ficamos alertas sobre o que fazemos para perpetuar o status quo e como podemos alterá-lo (Jean BOLEN, 2003, p. 32-33).

Pensamos, então, que a reinserção desta possibilidade de uma comunicação orgânica - circular/cíclica e que remete a um centro comum 
- possibilitaria a superação de um desencontro típico da simples troca de informação quando isolada em si mesma. Michel Maffesoli (2003, p. 14) defende que há uma relação importante e profunda entre os termos informação - "dar forma" e "o utilitário" - e comunicação - "tornar comum" e "estar-junto".

Assim, fala-se de informação sem pensar no que significa pôr em forma, e fala-se de comunicação sem referência à criação desse destino comum. $O$ essencial é deixado de lado. Desaparece o elemento participativo, a partilha, o laço social. $O$ fato de que essas palavras se imponham, contra os que as utilizam e controlam, é um indício, um sintoma, de algo importante: a prevalência do vivido em relação aos protagonistas do terreno intelectual. Na verdade, os intelectuais moralistas e politicamente corretos são obrigados a utilizar esses termos, pois o espírito do tempo está na forma comum, impregna esse comportamento relacional e estabelece um modo de vida. Comunicação e informação descrevem um modus vivendi característico da pós-modernidade (Michel MAFFESOLI, 2003, p.14).

Maffesoli chama de "potência subterrânea" a força comunicativa que reestabelece a informação no campo da comunhão e da partilha. Segundo ele, "como se diz no jargão da sociologia da comunicação, a emissão pode controlar efetivamente a recepção", porém de forma segmentada e limitada, pois "na prática, a informação só consegue unir microgrupos, microcosmos, universos segmentados". O universalismo dá lugar ao global. A vida cotidiana, o "fazer parte" e a identificação pessoal com o quê é informado, determinam as interações presentes no ato comunicativo e tudo isto integra o imaginário social (Michel MAFFESOLI, 2003, p. 15).

Em um dos trechos do estatuto de intenções do movimento do Milionésimo Círculo é colocado que:

Os círculos incentivam a conexão e a cooperação entre seus membros e inspiram soluções compassivas para os problemas individuais, comunitários e mundiais. Nós acreditamos que os círculos apoiam cada membro para que esta/este encontre sua própria voz e viva com mais coragem, e intencione: semear e cultivar círculos, sempre que possível, a fim de cultivar igualdade, meios de vida sustentáveis, 
preservação e paz para todos [...] conectar círculos para que eles possam reconhecer a si mesmos como partes de um movimento maior para mudar a consciência do mundo4.

Observa-se aqui a preocupação com a subjetividade das mulheres, mas, não de forma a isolar as atitudes individuais. Há um estímulo à manifestação coletiva do que é apreendido nos círculos. Isso propicia um movimento de mudança ética normativa na cultura e no imaginário, visto que a propagação de uma forma mais orgânica/sustentável de relacionar-se consigo e com o mundo estabelece um novo paradigma que contrapõe a egocracia típica do sistema patriarcalista.

Para Regina Célia Di Ciommo (2003, p. 428), “é necessário considerar o enraizamento antropossocial do conhecimento físico e o enraizamento físico da realidade antropossocial" e que isso se relaciona à noção de que o ser humano é um ser complexo. Citando Edgar Morin, ela complementa a reflexão com a afirmação de que "Homo é complexo bioantropológico e biossociocultural" e, assim, possuidor de muitas dimensões, indo além do que é complementar, mas, também do que é antagônico:

A realidade antropossocial é multidimensional; ela contém, sempre, uma dimensão individual, uma dimensão social e uma dimensão biológica, o que se evidencia especialmente na análise da conexão entre a mulher, a natureza e a cultura, em que se destacam os aspectos de complementação e antagonismo necessariamente irreconciliáveis (Regina DI CIOMMO, 2003, p. 428).

Essa quebra de paradigma encontrada nos processos comunicacionais dos círculos de mulheres pode também ser associada às ideias de Dominique Wolton (2010, p. 25) ao dizer que anteriormente as relações sociais e culturais relativamente estáveis eram a condição para o estabe-

4 Original em inglês: "Circles encourage connection and cooperation among their members and inspire compassionate solutions to individual, community and world problems. We believe that circles support each member to find her or his own voice and to live more courageously, and intend: to seed and nurture circles, wherever possible, in order to cultivate equality, sustainable livelihoods, preservation of the earth and peace for all. To connect circles so they may know themselves as a part of a larger movement to shift consciousness in the world." Disponível em: <http://millionthcircle.org/About/intentions.html>. Acesso em: 20 maio 2016. 
lecimento dos laços sociais. Porém, afirma também que nas sociedades contemporâneas, ocorre o oposto, pois tudo está em interação.

Os processos de informação e de comunicação contribuem para estruturar, por meio das múltiplas interações, um novo espaço público baseado num vínculo social mais dinâmico e frágil. A valorização do conceito de convivência ajuda a renovar a reflexão sobre a natureza do laço social nas sociedades contemporâneas, nas quais as interações entre os protagonistas são mais numerosas e contraditórias (Dominique WOLTON, 2010, p. 25).

Ele indica também o paradoxo na questão de que a comunicação e a interatividade acabam por reger o mundo, sendo inclusive "um modelo de sociedade" que, se por um lado reúne, ao mesmo tempo precisa lidar com os extremismos de opiniões e posicionamentos.

Este novo paradigma propõe um modelo distinto da visão mecanicista imposta pelo modo de pensar e agir racionalista/dualista. Não mais o "masculino vs. feminino"; "luz vs. sombra", "espírito vs. corpo", "razão vs. instinto", "vida vs. morte” em eterna oposição. A grande proposta dos círculos de mulheres é desenvolver as relações de complementariedade e de aceitação das dualidades encontradas entre os "pares" acima citados. Ademais, a diversidade e os antagonismos são vivenciados. A mediação da comunicação e das relações de todos os círculos ocorre em seu centro. É do centro que tudo nasce e é para o centro que tudo retorna. Dito isto, fica claro o quanto a dinâmica circular feminina difere das formas lineares ou piramidais (verticais), patriarcais, onde a referência é o líder do grupo, um indivíduo que "chefia” toda uma coletividade.

\section{SOBRE ECOFEMINISMO, TEOLOGIA FEMINISTA E A CONSTRUÇÃO DE UMA ECOESPIRITUALIDADE}

Podemos dizer que o movimento dos círculos de mulheres tem uma ligação com o feminismo, mas, nem todos os círculos se consideram feministas. As causas são muitas, mas, nos levam a refletir se essa rejeição não seria uma consequência da desinformação ou sobre o que seja o Feminismo ou ainda de qual das vertentes do feminismo se trata. 
Jean Shinoda Bolen, ao introduzir a questão da capacidade dos círculos em contribuir para uma mudança do mundo, cita um pensamento da escritora Carol Lee Flinders: “O feminismo pega fogo quando se nutre de sua espiritualidade inerente. Quando não o faz, é apenas mais uma forma de política e a política nunca alimentou nossas carências mais profundas" (Carol FLINDERS apud Jean BOLEN, 2003, p. 24). Desta forma, questionamos: não seria a estrutura filosófica da vertente espiritualista do ecofeminismo a mais adequada ao movimento dos círculos de mulheres?

Para ilustrar ainda mais nossa reflexão, recorremos a uma das mais proeminentes figuras do movimento ecofeminista na atualidade, a física e ativista ambientalista Vandana Shiva que, juntamente com a socióloga alemã María Mies, é autora de Ecofeminismo, um livro "referência" sobre o tema:

Uma perspectiva ecofeminista apresenta a necessidade de uma nova cosmologia que reconhece que a vida na natureza (incluindo os seres humanos) mantém-se por meio da cooperação, cuidado e amor mútuos. Somente deste modo estaremos habilitados a respeitar e a preservar a diversidade de todas as formas de vida, bem como das suas expressões culturais, como fontes verdadeiras do nosso bem estar e felicidade. Para alcançar este fim, as ecofeministas utilizam metáforas como "re-tecer o mundo", "curar as feridas", religar e interligar a "teia" (María MIES; Vandana SHIVA, 1993, p. 15).

Essa perspectiva propõe uma reintegração do ser humano - e não somente das mulheres - à Natureza. O ser humano deixa de ver-se como algo alheio ao restante dos seres existentes no planeta e tem a chance de reconhecer-se como aquele que faz parte. Essa possibilidade encontra ressonância nas características de religiões nativistas que, diferentemente das religiões abrâamicas, não concebem uma natureza humana dissociada na própria Natureza. Através desta visão a espiritualidade ecofeminista “esforça-se por 'curar a Terra-Mãe' e por re-encantar o mundo, o que significa desfazer o processo de desencantamento, que Max Weber viu como o inevitável processo de racionalização europeu" (María MIES; Vandana SHIVA, 1993, p. 30). 
Os círculos de mulheres promovem, em sua maioria, a visão comum a muitas culturas de que tudo é sagrado e interdependente. Ademais, no que tange à teologia ecofeminista presente em muitos dos círculos, é o próprio planeta a divindade em si, visto como um organismo vivo e feminino.

Na Antiguidade, o princípio feminino na imagem da Deusa simbolizava o princípio do relacionamento - a conexão oculta existente entre todas as coisas. Em segundo lugar, simbolizava a justiça, a sabedoria e a compaixão. Em terceiro, e principalmente, o princípio feminino era identificado com a dimensão invisível que existe para além do mundo conhecido - uma dimensão que pode ser vista como uma vasta e invisível matriz ou teia, ligando o espírito não-manifesto à matéria manifesta. A palavra então usada para identificar essa matriz era Grande Mãe ou Deusa; posteriormente, passou a ser chamada de Alma. O princípio feminino oferece uma imagem da integração, sacralidade e inviolabilidade de toda a vida; o mundo dos fenômenos (natureza, matéria, corpo) era visto como sagrado por ser a teofania ou manifestação do espírito cósmico (Anne BARING; Jules CASHFORD, 1993).

A Deusa é representada por divindades ctônicas, tal como Gaia (panteão grego) ou Pachamama (panteão ameríndio) e também por diferentes aspectos da Deusa, como por exemplo, os aspectos da tecelã, da mantenedora ou da ceifeira da vida, ou seja, a morte. Assim, podemos dizer que a espiritualidade nos círculos é ao mesmo tempo monoteísta - ao considerar o planeta como divindade suprema - e também politeísta5, visto que admite a diversidade de deidades e panteões.

Portanto, o chamado Sagrado Feminino também é interdependente e complexo. Isto reforça o processo de "invaginação do sentido" (Michel MAFFESOLI, 2010) - de natureza trágica típica do regime noturno do imaginário social - e sua relação com as práticas da espiritualidade feminina presentes nos círculos de mulheres.

5 O tema da ambivalência monoteísmo/politeísmo no mundo pré-socrático, inclusive nas culturas minoicas, é discutido por Riane Eisler em "O cálice e a espada" (1989). A noção de sagrado deste período tem influência direta na construção da espiritualidade de grande parte dos círculos de mulheres contemporâneos. 
Importante ressaltar que em muitos dos círculos há uma preocupação em nutrir o que Ivone Gebara (1997, p.101) chama de "Biodiversidade Religiosa". As divindades femininas têm uma importância essencial nas práticas e servem, inclusive, como referência identitária para as mulheres. Alguns círculos incluem divindades masculinas em suas práticas, contudo, os deuses não possuem o mesmo protagonismo das deidades femininas.

Concordamos com Ivone Gebara (1997, p. 108), pois "as teologias feministas são parte do tecido e não podem reproduzir tendências universalizantes e dominadoras". Já Rosemary Radford Ruether (2000, p. 19) reforça a questão quando diz que é preciso "rejeitar o que for opressivo, mas, também fazer uma síntese criativa do que for liberalizante em nossas heranças". Ela destaca também que mulheres de diferentes credos e culturas buscam estabelecer de maneira positiva a reciprocidade entre sínteses que, mesmo que distintas, são também complementares.

Apenas dessa forma, poderemos começar a saber como ser verdadeiras amigas e irmãs das mulheres - do povo - de outros mundos. Não mais como opressores, tentando suprimir as identidades de outros povos, mas também não como "páginas em branco" à procura do preenchimento de nosso vazio às custas dos outros (Rosemary RUETHER, 2000, p. 19).

A afirmação acima possui relações diretas com as intenções do movimento dos círculos de mulheres, pois o a inter-relação é uma das bases em suas constituições.

\section{CONCLUSÃO}

Ao concluirmos este trabalho, parece-nos que a complexidade se mostra qualidade intrínseca do movimento de círculos de mulheres: seja na comunicação, na estrutura imaginária ou mesmo na teologia e prática da espiritualidade feminina.

As teorias usadas no desenvolvimento de nossas reflexões se mostraram adequadas ao que nos propusemos, pois também fazem parte desta forma não "absoluta" de ver o mundo e suas nuances sócio-his- 
tóricas, discursivas e interpretativas. Usando um conceito maffesoliano, o "progressivo" parece dar sentido às relações na pós-modernidade e os círculos de mulheres podem ser incluídos neste paradigma que, do ponto de vista mecanicista, possui caráter indeterminado (ou indomável); mas, que na perspectiva do imaginário social, mostra um coerente sentido lógico.

A ideologia presente na estruturação do movimento do "Milionésimo Círculo" se mostra também bastante relacionada aos meandros socioculturais da pós-modernidade.

Ao contrário das relações pautadas pelo linear/fálico/vertical percebe-se a manifestação do cíclico/uterino/horizontal, porém, não de forma totalmente oposta, mas, sim propondo uma complementariedade. O mesmo acontece na forma de comunicação entre as mulheres dentro dos círculos e, com consequência, também fora deles.

Acreditamos que essa espécie de comunicação orgânica - advinda das rodas xamânicas e absorvida pelo movimento de círculos de mulheres - é um tema que muito pode contribuir para os estudos da comunicação, bem como para os estudos do imaginário, do ecofeminismo e da própria compreensão da espiritualidade feminina.

Dito isto, pretendemos estender nossas pesquisas nesta direção e na produção de trabalhos futuros.

\section{REFERÊNCIAS}

BARING, Anne; CASHFORD, Jules. The Myth of Goddess: Evolution of an image. London: Penguin Books, 1993.

BOLEN, Jean Shinoda. O milionésimo círculo: como transformar a nós mesmas e ao mundo: um guia para círculos de mulheres. São Paulo: TRIOM, 2003.

CHEVALIER, Jean. Diccionario de los símbolos. Barcelona: Editorial Herder, 1986.

DI CIOMMO, Regina Célia. Ecofeminismo e Educação Ambiental. São Paulo: Editorial Cone Sul, 1999.

DI CIOMMO, Regina Célia. Relações de gênero, meio ambiente e a teoria da complexidade. Estudos Feministas, v. 11, n. 2, p. 423, jan. 2003. ISSN 0104-026X. Disponível em: <https://periodicos.ufsc.br/index.php/ref/article/view/S0104-026X2003000200005>. Acesso em: 15 jun. 2016.

GEBARA, Ivone. Teologia ecofeminista: ensaio para repensar o Conhecimento e a Religião. São Paulo: Olho D’água, 1997. 
JUNG, Carl Gustav. Obras completas de C.G. Jung. Volume XI/1: Psicologia e religião. Petrópolis: Editora Vozes, 1978.

MAFFESOLI, Michel. Saturação. São Paulo: Iluminuras, 2010.

MAFFESOLI, Michel. A comunicação sem fim (teoria pós-moderna da comunicação). FAMECOS, 20, abr.2003. Disponível em: http://revistaseletronicas.pucrs.br/ojs/index. php/revistafamecos/article/viewFile/3198/2463 . Acesso em: 20 nov. 2014.

MILES, Maria; SHIVA, Vandana. Ecofeminismo. Lisboa: Instituto Piaget, 1993.

RUETHER, Rosemary Radford. Mulheres curando a Terra: Mulheres do Terceiro Mundo na ecologia, no feminismo e na religião. São Paulo: Paulinas, 2000.

THOMPSON, John. Ideologia e Cultura Moderna. São Paulo: Editora Vozes, 2011. WOLTON, Dominique. Informar não é comunicar. São Paulo: Sumus, 2010.

Submetido em: 11-05-2017

Aceito em: 23-6-2017 